\title{
Morphometric Features of Patent Foramen Ovale as a Risk Factor of Cerebrovascular Accidents: A Systematic Review and Meta-Analysis
}

\author{
Mateusz K. Hołda ${ }^{a}$ b Mateusz Koziej ${ }^{a}$ \\ ${ }^{a}$ Department of Anatomy, HEART, Heart Embryology and Anatomy Research Team, Jagiellonian University \\ Medical College, Kraków, Poland; ${ }^{b}$ Division of Cardiology, David Geffen School of Medicine, University of California, \\ Los Angeles, CA, USA
}

\section{Keywords}

Interatrial septum - Cryptogenic stroke - Ischemic stroke · Transesophageal echocardiography · Cardioembolic stroke

\begin{abstract}
Introduction: It is still disputable whether specific morphometric features of the patent foramen ovale (PFO) may stratify patients by the related probability that a discovered PFO is incidental or stroke related. Objective: We aimed to determine whether certain morphometrical characteristics of PFO are associated with an increased risk of cerebrovascular accidents, using a meta-analytical approach. Methods: We performed a systematic review of electronic databases for studies that compared morphometric parameters of PFO assessed by transesophageal echocardiography (TEE) in subjects with cryptogenic cerebrovascular accidents (Group 1) and control (Group 2). Data were extracted and pooled into a meta-analysis. Results: A total of 895 patients with PFO were reported (Group 1: 493, Group 2: 402). No difference was found in the PFO channel length (Group 1: 10.8 [8.612.9] $\mathrm{mm}$ vs. Group 2: 10.4 [9.1-11.7] $\mathrm{mm}$ ), as well as in PFO height measured at rest (Group 1:2.4 [1.5-3.3] mm vs. Group 2: 1.8 [1.4-2.2] mm). The PFO height measured during a Valsalva maneuver was larger in Group $1(3.5$ [2.8-4.1] mm) than in Group 2 (1.7 [1.2-2.2] mm). Also, the septal excursion distance was found to be larger in Group 1 (6.4 [5.1-7.8] mm)
\end{abstract}

than in Group 2 (3.1 [1.8-4.4] mm). The risk of cerebrovascular accident was higher in patients with PFO and concomitant septal aneurysm (OR 4.00; 95\% Cl 2.63-6.09; $p<0.001$ ) and with large right-to-left shunt PFO $(\mathrm{OR} 3.81 ; 95 \% \mathrm{Cl} 2.21-$ $6.55 ; p<0.001$ ), no such relationship was found for the presence of a Eustachian valve or Chiari's network (OR 1.90; 95\% $\mathrm{Cl} 0.90-4.05 ; p=0.094)$. Conclusions: The TEE may help in identifying PFO that are of high risk of cerebrovascular accident. Greater PFO height during a Valsalva maneuver, larger septal excursion distance, concomitant atrial septal aneurysm, and large right-to-left shunt are associated with strokerelated PFOs.

(c) 2020 S. Karger AG, Basel

\section{Introduction}

The patent foramen ovale (PFO), which is one of the anatomical variants of the interatrial septum [1], may be responsible for ischemic cerebrovascular events in a paradoxical embolism mechanism [2]. A cryptogenic stroke is defined as an ischemic stroke in which its cause remains unknown even despite extensive diagnostic workup. Such embolic strokes of undetermined source are diagnosed in approximately one-third of all stroke patients [3]. Several studies have confirmed a significant association between cryptogenic stroke and the presence of PFO, suggesting

\section{KARGER}

(c) 2020 S. Karger AG, Basel

karger@karger.com

www.karger.com/ced
Mateusz K. Hołda, MD, PhD

Department of Anatomy, HEART, Heart Embryology and Anatomy Research Team Jagiellonian University Medical College

Kopernika 12, PL-31-034 Kraków (Poland)

E-mail mkh@onet.eu 
that paradoxical emboli may be the prevailing cause of cryptogenic cerebrovascular accidents [4]. Two therapeutic options are available for the secondary prevention of PFO-related strokes, which are antiplatelet therapy and invasive PFO closure [5]. Three recent randomized clinical trials and meta-analyses of all the available studies showed that in selected patients with cryptogenic stroke, PFO closure is superior to medical therapy for the secondary prevention of stroke [6-11]. Nevertheless, as approximately one-third of PFO discovered in patients with cryptogenic stroke are likely to be incidental and unrelated to the stroke, the selection of patients in whom closing the PFO will be justified is still an unresolved issue [2].

General risk factors that may help to stratify patients by the related probability that a discovered PFO is incidental or stroke-related are well established and included in the Risk of Paradoxical Embolism score calculator [12]. However, a fundamental question about PFO-related factors increasing the probability that a PFO in a patient with cryptogenic stroke is the prime causative factor rather than an incidental finding still has no clear answer. It is still disputable whether specific morphometrical features of the PFO identified in transesophageal echocardiography (TEE), such as channel length, height, or degree of shunt, may contribute to the ischemic cerebrovascular events [13-16]. Therefore, here we aimed to determine whether certain morphometrical characteristics of PFO are associated with increased risk of cerebrovascular accidents using a meta-analytical approach.

\section{Methods}

The authors declare that all supporting data are available within the article and its online supplementary files (for all online suppl. material, see www.karger.com/doi/10.1159/000506433).

\section{Search Strategy}

A systematic literature search of the PubMed, EMBASE, Scopus, ScienceDirect, and Web of Science databases was conducted independently by 2 authors using PRISMA guidelines [17]. The PubMed search strategy is presented in online supplementary Table 1 . The search was not restricted by either language or time. We subsequently reviewed and evaluated the reference lists of all eligible articles to ensure the identification of all relevant studies.

\section{Eligibility Assessment and Data Extraction}

We initially removed duplicate reports of the same studies. In the next step, we required that the papers fulfilled the following criteria: they (1) were TEE studies, (2) evaluated the morphology of PFO in humans with PFO-related cerebrovascular accidents or cerebrovascular accidents of unknown origin, and (3) compared those data with noncerebrovascular accidents control patients.
The cerebrovascular accident was defined as either ischemic stroke or transient ischemic attack (reversible ischemic neurologic deficit). Furthermore, we excluded following types of papers: case reports and case series, reviews and meta-analyses, editorials, conference abstracts, and articles with incomplete or irrelevant data. Afterward, all authors independently extracted data from the included studies. The extracted data included the year, country of origin, study design, samples size, and characteristics of each group. The PFO-related morphometrical characteristics were extracted and included into the analysis when at least 3 studies have reported the same parameter. Articles that were eligible for inclusion in the meta-analysis were assessed by all authors. Any disagreements were addressed by obtaining a consensus.

\section{Statistical Analysis}

The STATISTICA version 13.1 software (StatSoft Inc., Tulsa, OK, USA) with an additional Medical Bundle and MetaXL version 5.3 from EpiGear International Pty, Ltd. (Wilston, QLD, Australia) was used for the calculations. For the morphometric data, calculations were conducted using Comprehensive Meta-Analysis version 3.0 by Biostat (Englewood, NJ, USA). The statistical analysis was based on a random effects model. A $p$ value $<0.05$ was considered to be statistically significant. Evidence of publication bias was investigated using a funnel plot and analyzed using the Egger method. We assessed heterogeneity among the included studies using the Cochrane Handbook's Q test and $I^{2}$ statistics. A $p<0.05$ or $I^{2}>50 \%$ was considered to indicate significant heterogeneity. Qualitative variables were compared using the $\chi^{2}$ test of proportions for categorical variables. The comparison of confidence intervals of any 2 morphometric data indicated differences between 2 groups, and if they overlapped, the difference was considered as statistically insignificant [18].

\section{Results}

An overview of the study selection process is summarized in Figure 1. We initially identified 1,976 of records through the database and reference searching. Of these, 1,077 of the records remained after the removal of the duplicates. A total of 793 records were excluded due to not meeting the main established criteria, and the remaining 284 full-text articles were assessed for eligibility. In the subsequent step, 275 papers were excluded for not being original studies or not containing suitable data for the meta-analysis. Each step of the selection process was validated by 2 authors to avoid any discrepancies. In case of incompatibilities, studies were reassessed by both authors to achieve the final agreement. In summary, 9 studies that met our initial criteria were identified and included in the meta-analysis [19-27].

The characteristics of the included studies are presented in Table 1. All studies were TEE case-control studies with a Valsalva maneuver and contrast injection performed on adult patients, but there was a significant dif- 


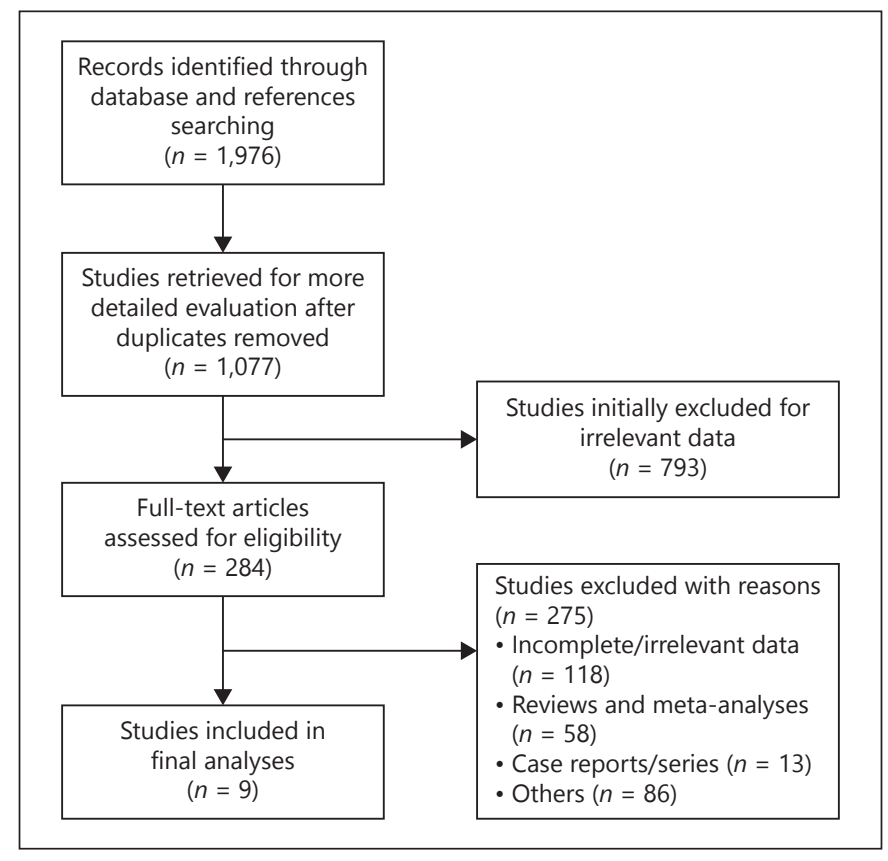

Fig. 1. Flow diagram demonstrating a selection of studies for metaanalysis. $n$, the number of records.

ference in patient age between studies. A total of 1,325 individuals were investigated in the included studies, among them 702 patients with cerebrovascular accidents (513 strokes, 189 transient ischemic attacks) and 623 control patients (without history of any cerebrovascular accident) were reported. All cerebrovascular accidents were defined as cryptogenic, but slightly different criteria were applied among included studies for this definition.

A total of 895 patients with PFO were reported. Two subgroups were distinguished in all the included studies: Group 1 - patients with cerebrovascular accident and with PFO identified in TEE; Group 2 - patients without any history of cerebrovascular accident and with PFO identified in TEE (Table 1). Group 1 included 493 patients and Group 2 included 402 individuals. All studies were reviewed to extract data regarding $\mathrm{PFO}$ morphology, especially: $\mathrm{PFO}$ channel length, PFO height, interatrial septum excursion distance, presence of atrial septal aneurysms, right-to-left shunt severity, presence of a prominent Eustachian valve, and presence of Chiari's network, with their division into the abovementioned groups (online suppl. Table 2).

\section{PFO Channel Length}

Five studies have reported PFO channel length (maximum overlap between septum primum and septum secundum) [21, 24-27]. No statistically significant differ- ence was found in the pooled mean length of the PFO channel between cerebrovascular accident and control groups (10.8 [8.6-12.9] vs. 10.4 [9.1-11.7] mm; Table 2).

\section{PFO Height (Septum Primum and Secundum Separation)}

The PFO height (or size) may be defined as a separation between the septum primum and secundum measured either at rest or during a Valsalva maneuver. Values for PFO height at rest were reported in 5 studies [22, 2427]. No statistically significant difference was found in the pooled mean PFO height measured at rest between cerebrovascular accident and control groups (2.4 [1.5$3.3]$ vs. 1.8 [1.4-2.2] $\mathrm{mm}$; Table 2).

The PFO height measured during Valsalva maneuver was given in 3 studies [19, 21, 25]. There was significantly larger pooled mean PFO height during a Valsalva maneuver in the cerebrovascular accident group than in the controls (3.5 [2.8-4.1] vs. 1.7 [1.2-2.2] mm; Table 2$)$.

\section{Septal Excursion Distance}

The interatrial septum excursion distance (or mobility of the fossa ovalis), measured as a distance between the plane of the interatrial septum (septum primum) and the maximum bulging into the left or the right atrium, was reported in 3 studies [19, 22, 26]. A significantly larger pooled mean septal excursion distance was found in the cerebrovascular accident group than in the controls (6.4 [5.1-7.8] vs. 3.1 [1.8-4.4] mm; Table 2).

\section{Presence of Atrial Septal Aneurysm}

The cooccurrence of PFO and atrial septal aneurysm was reported in 7 studies [20-22, 24-27]. Definition of the aneurysmal interatrial septum was slightly different between studies (a total excursion cutoff value ranging from 11 to $15 \mathrm{~mm}$ ). A total of 147 atrial septal aneurysms were identified among the cerebrovascular accident group, with a pooled prevalence of $35.4 \%$ (95\% CI $25.8-$ $45.7 \%$; random-effects model, $I^{2}=76 \%, p<0.001$ ), and 51 atrial septal aneurysms were identified in the controls, with a pooled prevalence of $14.3 \%$ (95\% CI 9.9-19.3\%; random-effects model, $\left.I^{2}=32 \%, p=0.18\right)$. After metaanalysis, the risk of cerebrovascular accident was higher in patients with PFO and concomitant septal aneurysm than in patients with $\mathrm{PFO}$, but without septal aneurysm (OR 4.00; 95\% CI 2.63-6.09; $p<0.001$; random-effect model; Fig. 2). No evidence of heterogeneity was found in the analysis $\left(I^{2}=14.63 \% ; p=0.318\right)$. Funnel plot analysis does not reveal a significant publication bias influencing the data (Egger's test: $p=0.758$ ). 
Table 1. Characteristics of studies included into meta-analysis

\begin{tabular}{|c|c|c|c|c|c|c|c|c|c|c|c|}
\hline Study & Year & Country & $\begin{array}{l}\text { Number of } \\
\text { patients with } \\
\text { cryptogenic } \\
\text { CVAs (stroke/ } \\
\text { TIA) (\% males) }\end{array}$ & $\begin{array}{l}\text { CVA group } \\
\text { characteristic }\end{array}$ & $\begin{array}{l}\text { Age of CVA } \\
\text { patients, years, } \\
\text { mean } \pm \text { SD }\end{array}$ & $\begin{array}{l}\text { Number of } \\
\text { non-CVA } \\
\text { control } \\
\text { patients } \\
\text { (\% males) }\end{array}$ & $\begin{array}{l}\text { Non-CVA } \\
\text { group } \\
\text { characteristic }\end{array}$ & $\begin{array}{l}\text { Age of } \\
\text { non-CVA } \\
\text { patients, } \\
\text { years, } \\
\text { mean } \pm S D\end{array}$ & $\begin{array}{l}\text { Total } \\
\text { number } \\
\text { of patients } \\
\text { with PFO }\end{array}$ & $\begin{array}{l}\text { Number } \\
\text { of CVA } \\
\text { patients } \\
\text { with PFO } \\
\text { (Group 1) }\end{array}$ & $\begin{array}{l}\text { Number of } \\
\text { non-CVA } \\
\text { patients } \\
\text { with PFO } \\
\text { (Group 2) }\end{array}$ \\
\hline $\begin{array}{l}\text { Schuchlenz } \\
\text { et al. [19] }\end{array}$ & 2000 & Austria & $\begin{array}{l}121(66 / 55) \\
(63.6)\end{array}$ & $\begin{array}{l}\text { Young ( }<60 \text { years) } \\
\text { consecutive patients } \\
\text { with unexplained } \\
\text { CVA referred } \\
\text { for TEE }\end{array}$ & $<60$ & $123(52.8)$ & $\begin{array}{l}\text { Young ( }<60 \text { years) } \\
\text { consecutive } \\
\text { patients with no } \\
\text { history of any } \\
\text { CVA and performed } \\
\text { TEE, that was } \\
\text { free of cardiac } \\
\text { abnormalities, except } \\
\text { for PFO or ASA }\end{array}$ & $41 \pm 12$ & 125 & 87 & 38 \\
\hline $\begin{array}{l}\text { Cerrato } \\
\text { et al. [20] }\end{array}$ & 2002 & Italy & $\begin{array}{l}175(136 / 39) \\
(50.3)\end{array}$ & $\begin{array}{l}\text { Consecutive patients } \\
\text { with unexplained } \\
\text { CVA referred for } \\
\text { TEE }\end{array}$ & $49.7 \pm 12$ & $78(51.3)$ & $\begin{array}{l}\text { Consecutive } \\
\text { patients with no } \\
\text { history of any } \\
\text { CVA referred } \\
\text { for TEE }\end{array}$ & $53.2 \pm 12$ & 68 & 55 & 13 \\
\hline $\begin{array}{l}\text { Natanzon } \\
\text { et al. [21] }\end{array}$ & 2003 & USA & $\begin{array}{l}36(31 / 5) \\
(\mathrm{n} / \mathrm{r})\end{array}$ & $\begin{array}{l}\text { Consecutive PFO } \\
\text { patients with } \\
\text { unexplained CVA } \\
\text { referred for TEE }\end{array}$ & $56.8 \pm 18.3$ & $42(\mathrm{n} / \mathrm{r})$ & $\begin{array}{l}\text { Consecutive patients } \\
\text { with no history of } \\
\text { any CVA referred } \\
\text { for TEE with PFO } \\
\text { as an incidental } \\
\text { finding }\end{array}$ & $58.2 \pm 17.6$ & 78 & 36 & 42 \\
\hline $\begin{array}{l}\text { Mesa } \\
\text { et al. [22] }\end{array}$ & 2003 & Spain & $\begin{array}{l}55(55 / 0) \\
(50.9)\end{array}$ & $\begin{array}{l}\text { Young ( }<50 \text { years) } \\
\text { consecutive } \\
\text { patients with } \\
\text { clinical suspicion } \\
\text { of stroke that } \\
\text { was confirmed }\end{array}$ & $40.1 \pm 10$ & $35(37.1)$ & $\begin{array}{l}\text { Young }(<50 \text { years }) \\
\text { consecutive patients } \\
\text { with clinically } \\
\text { suspected stroke } \\
\text { in whom ischemia } \\
\text { CVA was excluded }\end{array}$ & $37.7 \pm 11.3$ & 30 & 23 & 7 \\
\hline $\begin{array}{l}\text { Fazlinezhad } \\
\text { et al. [23] }\end{array}$ & 2009 & Iran & $\begin{array}{l}48(31 / 17) \\
(52.1)\end{array}$ & $\begin{array}{l}\text { Simple random } \\
\text { sampling study } \\
\text { evaluated young } \\
\text { adult (15-45 years) } \\
\text { patients with CVA }\end{array}$ & $34.8 \pm 9.4$ & $57(47.4)$ & $\begin{array}{l}\text { Young adult } \\
\text { (15-45 years) } \\
\text { consecutive patients } \\
\text { who underwent TEE } \\
\text { due to causes } \\
\text { other than CVAs }\end{array}$ & $33 \pm 9.8$ & 39 & 25 & 14 \\
\hline $\begin{array}{l}\text { Goel } \\
\text { et al. [24] }\end{array}$ & 2009 & USA & $\begin{array}{l}58(39 / 19) \\
(53.4)\end{array}$ & $\begin{array}{l}\text { Patients selected } \\
\text { from consecutive } \\
\text { patients who } \\
\text { undergone PFO } \\
\text { closure and TEE }\end{array}$ & $54 \pm 16$ & $58(63.8)$ & $\begin{array}{l}\text { Consecutive patients } \\
\text { with PFOs identified } \\
\text { incidentally on TEE } \\
\text { and without any } \\
\text { histories of CVAs } \\
\text { or any other } \\
\text { embolic events }\end{array}$ & $61 \pm 15$ & 116 & 58 & 58 \\
\hline $\begin{array}{l}\text { Komar } \\
\text { et al. [25] }\end{array}$ & 2012 & Poland & $\begin{array}{l}88(58 / 30) \\
(45.5)\end{array}$ & $\begin{array}{l}\text { Consecutive PFO } \\
\text { patients with } \\
\text { unexplained CVA } \\
\text { referred for TEE }\end{array}$ & $36.1 \pm 16.2$ & $88(44.3)$ & $\begin{array}{l}\text { Patients matched for } \\
\text { gender and age who } \\
\text { underwent TEE for } \\
\text { other reasons than } \\
\text { CVA in whom } \\
\text { asymptomatic PFO } \\
\text { was identified as the } \\
\text { sole abnormality }\end{array}$ & $36.1 \pm 16.2$ & 176 & 88 & 88 \\
\hline $\begin{array}{l}\text { Bayar } \\
\text { et al. [26] }\end{array}$ & 2015 & Turkey & $\begin{array}{l}64(40 / 24) \\
(45.3)\end{array}$ & $\begin{array}{l}\text { Consecutive PFO } \\
\text { patients with } \\
\text { unexplained CVA } \\
\text { referred for TEE }\end{array}$ & $43.8 \pm 8.6$ & $92(54.3)$ & $\begin{array}{l}\text { Patients with PFO } \\
\text { diagnosed on TEE } \\
\text { with no history } \\
\text { of any CVA }\end{array}$ & $37.8 \pm 9.3$ & 156 & 64 & 92 \\
\hline $\begin{array}{l}\text { Nakayama } \\
\text { et al. [27] }\end{array}$ & 2019 & Japan & $\begin{array}{l}57(57 / 0) \\
(42.1)\end{array}$ & $\begin{array}{l}\text { Consecutive patients } \\
\text { with PFO who were } \\
\text { scheduled for } \\
\text { transcatheter closure } \\
\text { for cryptogenic } \\
\text { stroke }\end{array}$ & $50 \pm 14$ & $50(52.0)$ & $\begin{array}{l}\text { Consecutive } \\
\text { patients without } \\
\text { CVA but with PFO } \\
\text { who were scheduled } \\
\text { for transcatheter } \\
\text { closure for migraine }\end{array}$ & $42 \pm 18$ & 107 & 57 & 50 \\
\hline
\end{tabular}

CVA, cerebrovascular accident; TIA, transient ischemic attack; PFO, patent foramen ovale; TEE, transesophageal echocardiography; ASA, atrial septal aneurysm; n/r, not reported. 
Table 2. Pooled mean PFO-related dimensions in analyzed subgroups

\begin{tabular}{lcc}
\hline Parameter & $\begin{array}{c}\text { CVA patients with } \\
\text { PFO (Group 1) }\end{array}$ & $\begin{array}{c}\text { Non-CVA patients with PFO } \\
\text { (controls) (Group 2) }\end{array}$ \\
\hline PFO channel length & $5(303)$ & $5(330)$ \\
$\quad$ Number of studies (number of patients) & $10.8(8.6-12.9)$ & $10.4(9.1-11.7)$ \\
$\quad$ Pooled mean length, mm (95\% CI) & 31.9 & 11.4 \\
$I^{2}, \%$ & $5(290)$ & $5(295)$ \\
PFO height at rest & $2.4(1.5-3.3)$ & 55.1 \\
Number of studies (number of patients) & 3.9 & $3(1.4-2.2)$ \\
Pooled mean height at rest, mm (95\% CI) & $3(211)$ & $1.7(1.2-2.2)$ \\
$I^{2}, \%$ & $3.5(2.8-4.1)$ & 0.0 \\
PFO height during Valsalva & 43.7 & $3(137)$ \\
Number of studies (number of patients) & $3(174)$ & $3.1(1.8-4.4)$ \\
Pooled mean height during Valsalva, mm (95\% CI) & $6.4(5.1-7.8)$ & 0.0 \\
$I^{2}, \%$ & 21.8 & \\
Septal excursion distance & & \\
Number of studies (number of patients) & & \\
Pooled mean excursion distance, mm (95\% CI) & & \\
$I^{2}, \%$ & & \\
\hline
\end{tabular}

CVA, cerebrovascular accident; PFO, patent foramen ovale.

Fig. 2. Forest plot representation of the results from the significant studies comparing presence of $\mathrm{PFO}$ with concomitant ASA in CVA patients and controls. Studies are displayed on the vertical and are marked with a square of proportional size to the study's calculated weight. The overall effect is lowermost and marked with a rhombus. PFO, patent foramen ovale; ASA, atrial septal aneurysm; CVA, cerebrovascular accident.

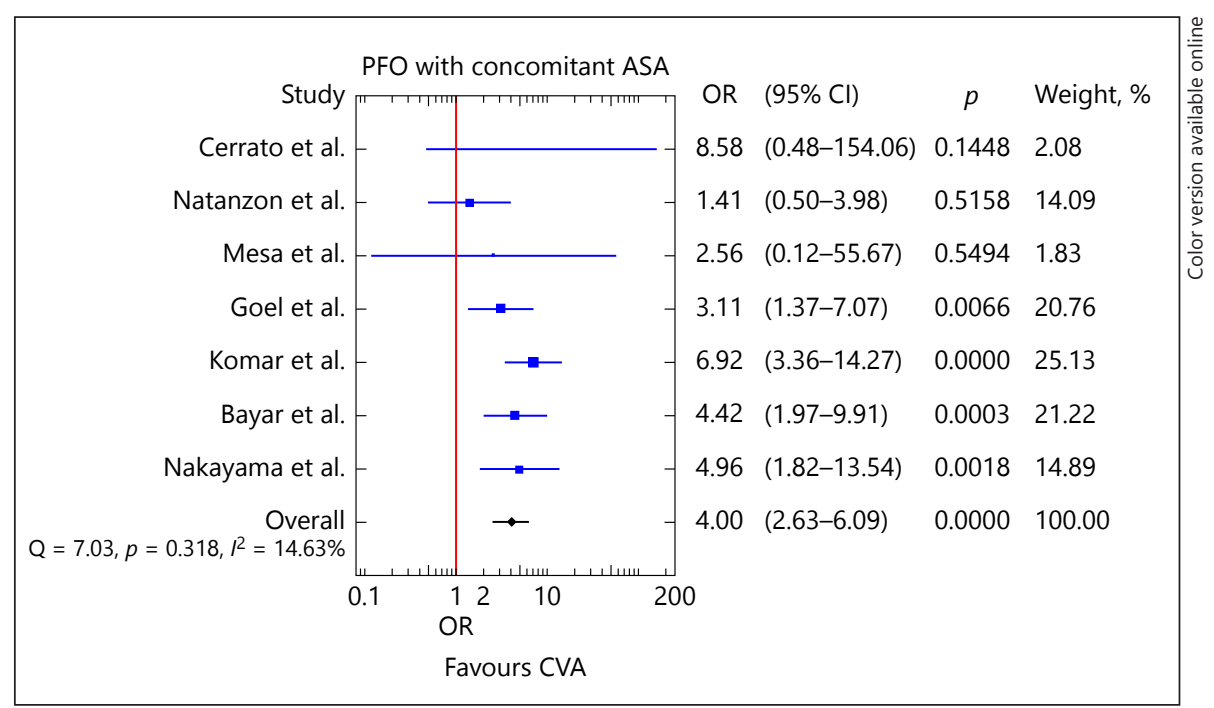

\section{Right-to-Left Shunt Severity}

Severity of right-to-left shunt via the PFO may be assessed based on counting the microbubbles passing to the left atrium. However, different quantitative criteria are adopted to determine the degree of shunt (online suppl. Table 2). Among all the included studies, 4 of them have used the same criterion and those were included in further calculations [20-22, 27]. If the number of crossing microbubbles was $<20$, the shunt was considered small; $>20$ microbubbles indicated a large shunt. A total of 110 patients with a large shunt were identified among the cerebrovascular accident group, with a pooled prevalence of $68.4 \%$ (95\% CI 50.8-83.7\%; random-effects model, $I^{2}=$ $81 \%, p<0.001$ ), and 42 individuals with a large shunt were identified in the control group, with a pooled prevalence of $37.8 \%$ (95\% CI 29.0-46.9\%; random-effects model, $\left.I^{2}=0 \%, p=0.64\right)$. After meta-analysis, the risk of cerebrovascular accident was higher in patients with a large shunt $\mathrm{PFO}$ than in patients with a small shunt $\mathrm{PFO}$ (OR 3.81; 95\% CI 2.21-6.55; $p<0.001$; random-effect model; 
Fig. 3. Forest plot representation of the results from the significant studies comparing shunt severity via PFO in CVA patients and controls. Studies are displayed on the vertical and are marked with a square of proportional size to the study's calculated weight. The overall effect is lowermost and marked with a rhombus. PFO, patent foramen ovale; CVA, cerebrovascular accident.

Fig. 4. Forest plot representation of the results from the significant studies comparing presence of $\mathrm{PFO}$ with concomitant Eustachian valve or Chiari's network in CVA patients and controls. Studies are displayed on the vertical and are marked with a square of proportional size to the study's calculated weight. The overall effect is lowermost and marked with a rhombus. PFO, patent foramen ovale; CVA, cerebrovascular accident.
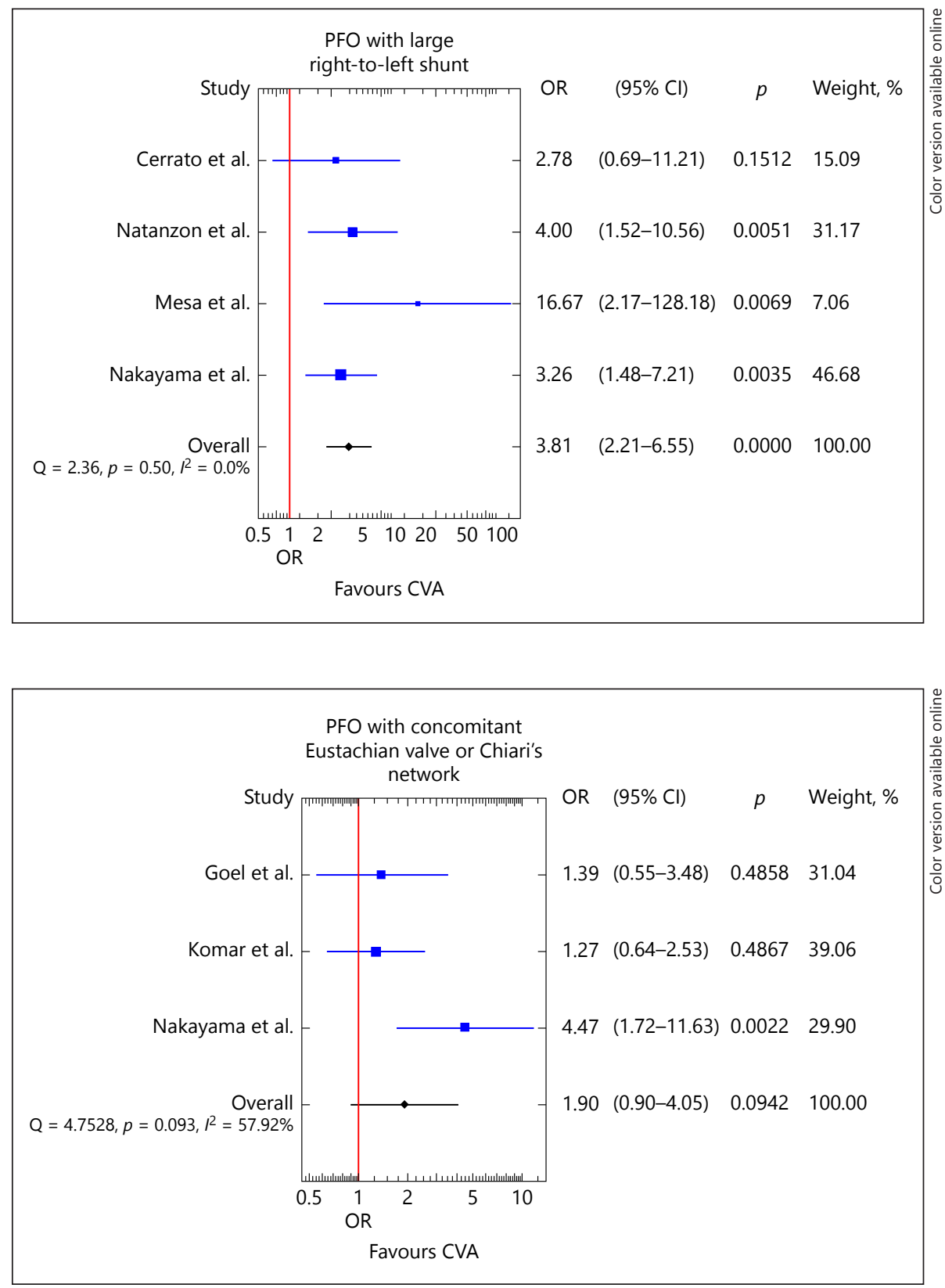

Fig. 3). No evidence of heterogeneity was found in the analysis $\left(I^{2}=0 \% ; p=0.50\right)$. Funnel plot analysis does not reveal a significant publication bias influencing the data (Egger's test: $p=0.292$ ).

\section{Presence of Eustachian Valve or Chiari's Network}

The presence of prominent Eustachian valve or Chiari's network was reported in 3 studies [24, 25, 27]. Due to discrepancies in data reporting, we were unable to separate the presence of the valve and network into 2 independent analyses and thus those structures were merged into 1 group. A total of 61 Eustachian valves or Chiari's networks were identified among the cerebrovascular accident group, with a pooled prevalence of $30.2 \%$ (95\% CI 20.0-41.4\%; random-effects model, $I^{2}=64 \%, p=0.06$ ), and 37 were identified in the controls, with a pooled prevalence of $19.1 \%$ (95\% CI 13.9-24.9\%; random-effects model, $I^{2}=0 \%, p=0.45$ ). After meta-analysis, no reliable association between the presence of Eustachian valve or Chiari's network and increased risk of cerebrovascular accident was found (OR 1.90; 95\% CI 0.90-4.05; $p=0.094$; random-effect model; Fig. 4). Significant heterogeneity 
was present in this analysis $\left(I^{2}=57.92 \%\right.$; $\left.p=0.093\right)$. Funnel plot analysis does not reveal a significant publication bias influencing the data (Egger's test: $p=0.516$ ).

\section{Discussion}

In this study, we have attempted to systematize and reanalyze the results of currently available studies concerning the influence of PFO-related morphometric features on the occurrence of cerebral ischemic events, which has not been previously performed. As a result of our research, high-risk transesophageal echocardiographic features of PFO were identified, which are large PFO height measured during a Valsalva maneuver $(\geq 2.8 \mathrm{~mm})$, interatrial septum hypermobility (large septal excursion distance or concomitant atrial septal aneurysm), and large right-to-left shunt via the PFO (>20 microbubbles). Unexpectedly, the length of the PFO and the presence of the Eustachian valve or Chiari's network did not differ between the analyzed groups, which undermines many previous concepts trying to determine, hypothetically or based on single-center, small studies, characteristics of high-risk PFOs [27-29].

Factors identified by our meta-analysis seem to indicate the joint mechanism responsible for PFO participation in cerebrovascular ischemic events. The paradoxical embolism phenomenon is an indisputable causative agent in PFO-related embolisms [30]. Several specific conditions must coexist to allow thromboembolism originating in the venous vasculature to travel through the interatrial septum into the systemic circulation. First the thrombus must reach the vicinity of the right aspect of the interatrial septum. The presence of the Eustachian valve, which in fetal life helps direct the flow of oxygenated blood superiorly and anteriorly (to bypass the pulmonary circulation) may theoretically favor paradoxical embolism. On the other hand, the occurrence of the Chiari's network spanned in the right atrium, depending on its position within atrium, may either direct the blood flow (and thrombi) toward the interatrial septum or act as a filter retaining thrombi [31]. Second the thrombus must squeeze through the relatively small tunnel located in the septum to reach the left atrium. The PFO, when present, is functionally closed due to higher blood pressure in left than right atrium [32]. Temporarily increased right atrial pressure opens the PFO. Based on the results of our meta-analyses, it is reasonable to say that multiplane wider opening of the PFO channel, expressed by its larger height and larger shunt, may be the main paradoxical embolism facilitating mechanism. Moreover, the presence of an atrial septal aneurysm causes drastic increase in PFO patency time, which in these cases opens not only during increased right atrium pressure, but practically every heartbeat. The hypermobile, less fixed, and more elastic septum that is associated with atrial septal aneurysm allows greater change in PFO channel dimensions and thus significantly contributes to the opening of the PFO [33].

The identification of high-risk PFO is crucial for choosing the right prevention or therapy strategies. It is well proven by the DEFENSE-PFO trial that PFO device closure in patients with high-risk PFO (defined as a concomitant presence of atrial septal aneurysm, septum hypermobility or PFO height measured at Valsalva $\geq 2 \mathrm{~mm}$ ) resulted in significantly better outcomes than pharmacological therapy in secondary stroke prevention [34]. Such a beneficial achievement for secondary stroke prevention brings further questions about the legitimacy of closing the high-risk PFO not only in "cryptogenic" patients but also in those with the presence of other potential causes of ischemic accidents or even for primary cerebrovascular events prevention [35]. Moreover, closure devices should be designed and produced considering the specific morphometric features of the interatrial septum and PFO, which are different in high-risk patients. Finally, it is still debatable whether primary preventive PFO closure should be performed. Indeed, there are no strong data from randomized clinical trials that may support this strategy, but many points to the benefits of preventative PFO closure [36]. The PFO closure for primary prevention should be especially considered in certain high-risk patients, the majority of which are young people. Patients with high tendency for venous thrombosis, vocational or recreational activities fostering right to left shunts (e.g., deep or professional divers, mountain climbers and pilots), unfavorable PFO morphological features or those who can expect a collateral benefit (e.g., migraine patients) should be strongly considered for primary preventive PFO closure [37]. In those cases, early PFO closure is effective, relatively simple, and safe procedure without major adverse effects that may prevent death or permanent disability while being cost-effective in longer perspective [36].

Our meta-analyses are not without limitations, which are caused by the initial imperfections in study design and methods of data reporting of each study included. First, the definition of cryptogenic cerebrovascular accidents was slightly different among the included studies and some discrepancies in the study group and control selection processes might affect the final results (Table 1). Second, due to the way in which the data were reported by 
the authors of identified studies, where strokes and transient ischemic attacks were mostly treated as 1 group, we were unable to separate data regarding only cryptogenic stroke; and thus all cerebrovascular accidents were analyzed in the current study. Moreover, our meta-analysis has investigated only those PFO-related parameters, which occurred in at least 3 different studies; therefore, it cannot be excluded that other features (such as septum primum thickness, septum secundum thickness and height, and ratios of selected measurements) may significantly affect an increased risk of cerebrovascular emboli. Additionally, the imaging method used (TEE), although it is recognized as a gold standard in interatrial septum evaluation, may affect the results of our meta-analyses due to potential differences in septum visualization and the views used, and thus modifications in measuring techniques between included studies [38]. Especially the definition of PFO shunt size varies significantly between studies and is highly subjective and poorly reproducible. Moreover, the mean age of the subjects included in each study group differed significantly between the groups and between studies. As the interatrial septum undergoes constant, lifelong remodeling, the size of the PFO may change over time and thus can influence the results of this study [39]. Also, we were unable to analyze for sex and ethnic differences in the PFO morphometry. Finally, the impact of other stroke risk factors (age, sex, comorbidity) and the mutual interaction of PFO morphological factors were not included in our one-factor analyzes, which should be considered in further studies.
In conclusion, our study demonstrated an association between PFO-related morphometric parameters and an increased risk of cryptogenic cerebrovascular accidents. Larger PFO height measured during a Valsalva maneuver and larger septal excursion distance are both associated with stroke-related PFOs. A PFO with concomitant atrial septal aneurysm and large right-to-left shunt via the PFO are risk factors that significantly increase the likelihood of ischemic cerebrovascular accidents.

\section{Statement of Ethics}

The ethical approval was not required for this type of study.

\section{Disclosure Statement}

The authors have no conflicts of interest to declare.

\section{Funding Sources}

Dr. Mateusz Hołda was supported by the Polish National Agency for Academic Exchange.

\section{Author Contributions}

M.K.H. and M.K.: conception and design of the work; data acquisition and analysis; drafting the manuscript; final approval of the article.

\section{References}

1 Klimek-Piotrowska W, Hołda MK, Koziej M, Piątek K, Hołda J. Anatomy of the true interatrial septum for transseptal access to the left atrium. Ann Anat. 2016 May;205:60-4.

2 Alsheikh-Ali AA, Thaler DE, Kent DM. Patent foramen ovale in cryptogenic stroke: incidental or pathogenic? Stroke. 2009 Jul;40(7): 2349-55.

3 Amarenco P. Underlying pathology of stroke of unknown cause (cryptogenic stroke). Cerebrovasc Dis. 2009;27 Suppl 1:97-103.

4 Overell JR, Bone I, Lees KR. Interatrial septal abnormalities and stroke: a meta-analysis of case-control studies. Neurology. 2000 Oct; 55(8):1172-9.

5 Mi MY, Block PC, Broderick JP. PFO Closure for Cryptogenic Stroke. N Engl J Med. 2018 Apr;378(17):1639-42.

6 Mas JL, Derumeaux G, Guillon B, Massardier E, Hosseini $\mathrm{H}$, Mechtouff $\mathrm{L}$, et al.; CLOSE Investigators. Patent Foramen Ovale Closure or Anticoagulation vs. Antiplatelets after Stroke. N Engl J Med. 2017 Sep;377(11): 1011-21.

7 Søndergaard L, Kasner SE, Rhodes JF, Andersen G, Iversen HK, Nielsen-Kudsk JE, et al.; Gore REDUCE Clinical Study Investigators. Patent Foramen Ovale Closure or Antiplatelet Therapy for Cryptogenic Stroke. N Engl J Med. 2017 Sep;377(11):1033-42.

8 Saver JL, Carroll JD, Thaler DE, Smalling RW, MacDonald LA, Marks DS, et al.; RESPECT Investigators. Long-Term Outcomes of Patent Foramen Ovale Closure or Medical Therapy after Stroke. N Engl J Med. 2017 Sep; 377(11):1022-32.

9 Ahmad Y, Howard JP, Arnold A, Shin MS, Cook C, Petraco R, et al. Patent foramen ovale closure vs. medical therapy for cryptogenic stroke: a meta-analysis of randomized controlled trials. Eur Heart J. 2018 May;39(18): 1638-49.

10 Vaduganathan M, Qamar A, Gupta A, Bajaj N, Golwala HB, Pandey A, et al. Patent Fora- men Ovale Closure for Secondary Prevention of Cryptogenic Stroke: Updated Meta-Analysis of Randomized Clinical Trials. Am J Med. 2018 May;131(5):575-7.

11 Saber H, Palla M, Kazemlou S, Azarpazhooh MR, Seraji-Bozorgzad N, Behrouz R. Network meta-analysis of patent foramen ovale management strategies in cryptogenic stroke. Neurology. 2018 Jul;91(1):e1-7.

12 Kent DM, Ruthazer R, Weimar C, Mas JL, Serena J, Homma S, et al. An index to identify stroke-related vs incidental patent foramen ovale in cryptogenic stroke. Neurology. 2013 Aug;81(7):619-25.

13 Wessler BS, Thaler DE, Ruthazer R, Weimar C, Di Tullio MR, Elkind MS, et al. Transesophageal echocardiography in cryptogenic stroke and patent foramen ovale: analysis of putative high-risk features from the risk of paradoxical embolism database. Circ Cardiovasc Imaging. 2014 Jan;7(1): $125-31$. 
14 Akhondi A, Gevorgyan R, Tseng CH, Slavin L, Dao C, Liebeskind DS, et al. The association of patent foramen ovale morphology and stroke size in patients with paradoxical embolism. Circ Cardiovasc Interv. 2010 Oct;3(5): 506-10.

15 Pristipino C, Sievert H, D’Ascenzo F, Mas JL, Meier B, Scacciatella P, et al.; European Association of Percutaneous Cardiovascular Interventions (EAPCI); European Stroke Organisation (ESO); European Heart Rhythm Association (EHRA); European Association for Cardiovascular Imaging (EACVI); Association for European Paediatric and Congenital Cardiology (AEPC); ESC Working group on GUCH; ESC Working group on Thrombosis; European Haematological Society (EHA). European position paper on the management of patients with patent foramen ovale. General approach and left circulation thromboembolism. Eur Heart J. 2018;14(13): 1389-402.

16 Wessler B, Thaler DE, Di Tullio MR, et al. PFO in cryptogenic stroke: an analysis of "high risk" features on transesophageal echocardiography in the risk of paradoxical embolism database. Stroke. 2013;44(2).

17 Liberati A, Altman DG, Tetzlaff J, Mulrow C, Gøtzsche PC, Ioannidis JP, et al. The PRISMA statement for reporting systematic reviews and meta-analyses of studies that evaluate health care interventions: explanation and elaboration. J Clin Epidemiol. 2009 Oct; 62(10):e1-34.

18 Henry BM, Tomaszewski KA, Walocha JA. Methods of Evidence-Based Anatomy: a guide to conducting systematic reviews and meta-analysis of anatomical studies. Ann Anat. 2016 May;205:16-21.

19 Schuchlenz HW, Weihs W, Horner S, Quehenberger $\mathrm{F}$. The association between the diameter of a patent foramen ovale and the risk of embolic cerebrovascular events. Am J Med. 2000 Oct;109(6):456-62.

20 Cerrato P, Imperiale D, Priano L, Mangiardi L, Morello M, Marson AM, et al. Transoesophageal echocardiography in patients without arterial and major cardiac sources of embolism: difference between stroke subtypes. Cerebrovasc Dis. 2002;13(3):17483.
21 Natanzon A, Goldman ME. Patent foramen ovale: anatomy versus pathophysiologywhich determines stroke risk? J Am Soc Echocardiogr. 2003 Jan;16(1):71-6.

22 Mesa Rubio D, Franco M, de Lezo J, et al. Prevalencia de foramen oval permeable en $\mathrm{pa}$ cientes jóvenes con accidente isquémico cerebral de causa desconocida. Rev Esp Cardiol. 2003;56(7):662-8.

23 Fazlinezhad A, Azimi S, Azarpazhooh M, Khajedaluee M, Kashani MM. Patent Foramen Ovale in Young Adults with Cryptogenic Stroke or Transient Ischemic Attack. J Tehran Univ Heart Cent. 2009;3:185-8.

24 Goel SS, Tuzcu EM, Shishehbor MH, de Oliveira EI, Borek PP, Krasuski RA, et al. Morphology of the patent foramen ovale in asymptomatic versus symptomatic (stroke or transient ischemic attack) patients. Am J Cardiol. 2009 Jan;103(1):124-9.

25 Komar M, Podolec P, Przewłocki T, Wilkołek P, Tomkiewicz-Pająk L, Motyl R. Transoesophageal echocardiography can help distinguish between patients with "symptomatic" and "asymptomatic" patent foramen ovale. Kardiol Pol. 2012;70(12):1258-63.

26 Bayar N, Arslan Ş, Çağırcı G, Erkal Z, Üreyen ÇM, Çay S, et al. Assessment of morphology of patent foramen ovale with transesophageal echocardiography in symptomatic and asymptomatic patients. J Stroke Cerebrovasc Dis. 2015 Jun;24(6):1282-6.

27 Nakayama R, Takaya Y, Akagi T, Watanabe N, Ikeda M, Nakagawa K, et al. Identification of High-Risk Patent Foramen Ovale Associated With Cryptogenic Stroke: Development of a Scoring System. J Am Soc Echocardiogr. 2019 Jul;32(7):811-6.

28 Falanga G, Carerj S, Oreto G, Khandheria BK, Zito C. How to Understand Patent Foramen Ovale Clinical Significance: part I. J Cardiovasc Echogr. 2014 Oct-Dec;24(4):114-21.

29 Rana BS, Shapiro LM, McCarthy KP, Ho SY Three-dimensional imaging of the atrial septum and patent foramen ovale anatomy: defining the morphological phenotypes of patent foramen ovale. Eur J Echocardiogr. 2010 Dec;11(10):i19-25.

30 Windecker S, Stortecky S, Meier B. Paradoxical embolism. J Am Coll Cardiol. 2014 Jul; 64(4):403-15.
31 Klimek-Piotrowska W, Hołda MK, Koziej M, Strona M. Anatomical barriers in the right atrium to the coronary sinus cannulation. PeerJ. 2016 Jan;3(1):e1548.

32 Rahman A, Jayasinghe R, Rajendran S. Paradoxical embolism via a patent foramen ovale: an important mechanism of cryptogenic strokes. Circ Cardiovasc Imaging. 2008 Sep; 1(2):e9-10.

33 Fox ER, Picard MH, Chow CM, Levine RA, Schwamm L, Kerr AJ. Interatrial septal mobility predicts larger shunts across patent foramen ovales: an analysis with transmitral Doppler scanning. Am Heart J. 2003 Apr; 145(4): 730-6.

34 Lee PH, Song JK, Kim JS, Heo R, Lee S, Kim $\mathrm{DH}$, et al. Cryptogenic Stroke and High-Risk Patent Foramen Ovale: the DEFENSE-PFO Trial. J Am Coll Cardiol. 2018 May;71(20): 2335-42.

35 Mojadidi MK, Zaman MO, Elgendy IY, Mahmoud AN, Patel NK, Agarwal N, et al. Cryptogenic Stroke and Patent Foramen Ovale. J Am Coll Cardiol. 2018 Mar;71(9):1035-43.

36 Nietlispach F, Meier B. Percutaneous closure of patent foramen ovale: an underutilized prevention? Eur Heart J. 2016 Jul;37(26): 2023-8.

37 Araszkiewicz A, Bartuś S, Demkow M, Grygier M, Huczek Z, Komar M, et al. Interventional closure of patent foramen ovale in prevention of thromboembolic events. Consensus document of the Association of Cardiovascular Interventions and the Section of Grown-up Congenital Heart Disease of the Polish Cardiac Society. Kardiol Pol. 2019 Nov;77(11):1094-105.

38 Silvestry FE, Cohen MS, Armsby LB, Burkule NJ, Fleishman CE, Hijazi ZM, et al.; American Society of Echocardiography; Society for Cardiac Angiography and Interventions. Guidelines for the Echocardiographic Assessment of Atrial Septal Defect and Patent Foramen Ovale: From the American Society of Echocardiography and Society for Cardiac Angiography and Interventions. J Am Soc Echocardiogr. 2015 Aug;28(8):910-58.

39 Hołda MK, Koziej M, Hołda J, Piątek K, Tyrak $\mathrm{K}$, Chołopiak W, et al. Atrial septal pouch Morphological features and clinical considerations. Int J Cardiol. 2016 Oct;220:337-42. 